\title{
Life cycle studies of Heptageniidae (Insecta: Ephemeroptera) in Kumbbakarai Stream of Western Ghats,Tamil Nadu, India
}

\author{
T. Sivaruban ${ }^{1}$, S. Barathy ${ }^{2}$, K. Venkataraman ${ }^{3} \&$ M. Arunachalam ${ }^{4}$ \\ 1,2,4 Sri Paramakalyani Centre for Environmental Sciences, Manonmaniam Sundaranar University, Alwarkurichi, Tamil Nadu 627412, \\ India \\ ${ }^{3}$ Centre for Research in Aquatic Entomology, Department of Zoology, Madura College, Madurai, Tamil Nadu 625011, India \\ Email: rooban2002@yahoo.com
}

\begin{abstract}
Life cycle studies of Epeorus sp., Afronurus kumbbakkaraiensis and Thalerosphyrus flowersi of the family Heptageniidae were conducted in the Kumbbakarai stream of Western Ghats, southern India. Epeorus sp. may have more than one univoltine brood since part of the eggs hatch in northeast monsoon period and the rest in the following summer. Life cycle of Afronurus kumbbakkaraiensis and Thalerosphyrus flowersi is basically multivoltine with asynchronous, overlapping genera. However, this study reveals the possible influence of summer in numerical reduction of Afronurus kumbbakkaraiensis and Thalerosphyrus flowersi.
\end{abstract}

Keywords: Ephemeroptera, Heptageniidae, life cycles.

Mayflies (Ephemeroptera) are abundant and diverse in most tropical Asian streams. They represent $30 \%$ of benthic populations (Dudgeon 1992) but little is known about their life history. Rawlinson (1939) gave a detailed account of breeding and life history of Ecdyonurus venosus. Harker (1952) studied the life histories of Ecdyonurus torrentis, Heptagenia lateralis and Rhithrogenia semicolorata and found that the last two

\author{
Date of publication (online): 26 September 2010 \\ Date of publication (print): 26 September 2010 \\ ISSN $0974-7907$ (online) | 0974-7893 (print) \\ Editor: B.A. Daniel \\ Manuscript details: \\ Ms \# 02380 \\ Received 01 January 2010 \\ Final revised received 20 July 2010 \\ Finally accepted 07 August 2010
}

Citation: Sivaruban, T., S. Barathy, K. Venkataraman \& M. Arunachalam (2010). Life cycle studies of Heptageniidae (Insecta: Ephemeroptera) in Kumbbakarai Stream of Western Ghats,Tamil Nadu, India. Journal of Threatened Taxa 2(10): 1223-1226.

Copyright: $\odot$ T. Sivaruban, S. Barathy, K.Venkataraman \& M. Arunachalam 2010. Creative Commons Attribution 3.0 Unported License. JoTT allows unrestricted use of this article in any medium for non-profit purposes, reproduction and distribution by providing adequate credit to the authors and the source of publication.

Acknowledgements: We thank Dr. K.G. Sivaramakrishnan for literature and critical comments.

\section{OPEN ACCESS I FREE DOWNLOAD (C) (1) (4)}

forms have univoltine life cycle. Epeorus pleuralis was also found to have univoltine life cycle (Minshall 1967). McCafferty \& Huff (1978) have given an account of the life cycle of Stenacron interpunctatum.

Bengstsson (1981) and Olechowska (1981) described the life cycles of Heptagenia fuscogrisea and Rhithrogena loyolaea respectively. Dudgeon (1996), Salas \& Dudgeon (2003) described the life cycles of Heptageniidae, Baetidae and Leptophlebiidae. This short communication deals with the life cycle pattern of Heptageniidae found in Kumbakkarai Stream of Western Ghats (11N $\left.\& 77^{\circ} 50^{\prime} \mathrm{E}\right)$ situated about $100 \mathrm{~km}$ west of Madurai, on the eastern side of Palni Hills at an altitude of $400 \mathrm{~m}$. A perennial hill stream cascades as Kumbakkarai falls and water temperature ranges from $25^{\circ}$ to $35^{\circ} \mathrm{C}$. This area receives 175 to $210 \mathrm{~cm}$ rainfall per year.

\section{Materials and Methods}

Quantitative samples were collected bimonthly during January - December 2006 randomly from ten cobbles of uniform size, in a stratified manner across the stream habitats. Individual cobbles were transferred from the stream bed to a hand net $(200 \mu m$ mesh) positioned immediately downstream, washed inside the net. Larvae collected from all cobbles were pooled and preserved in $70 \%$ alcohol.

Clifford (1969) method was followed and in the classification of stages, nymphs were grouped into four arbitrarily chosen developmental stages by appearance and development of the mesothoracic wing pads. Stage I nymphs lacked wing pads; stage II nymphs had wing pads but the lengths was shorter than the distance separating the two wing pads. Stage III nymphs had their wing pad length greater than the distance separating the two wing pads. Stage IV nymphs had darkened wing pads. Every stage is represented by several instars with the exception of stage IV, the last nymphal instar, where the tanned wing pads indicate impending emergence. Male and female nymphs were separated by looking at the genitalia and the nature of eyes. Eyes are very close in male; in female they are widely apart. 


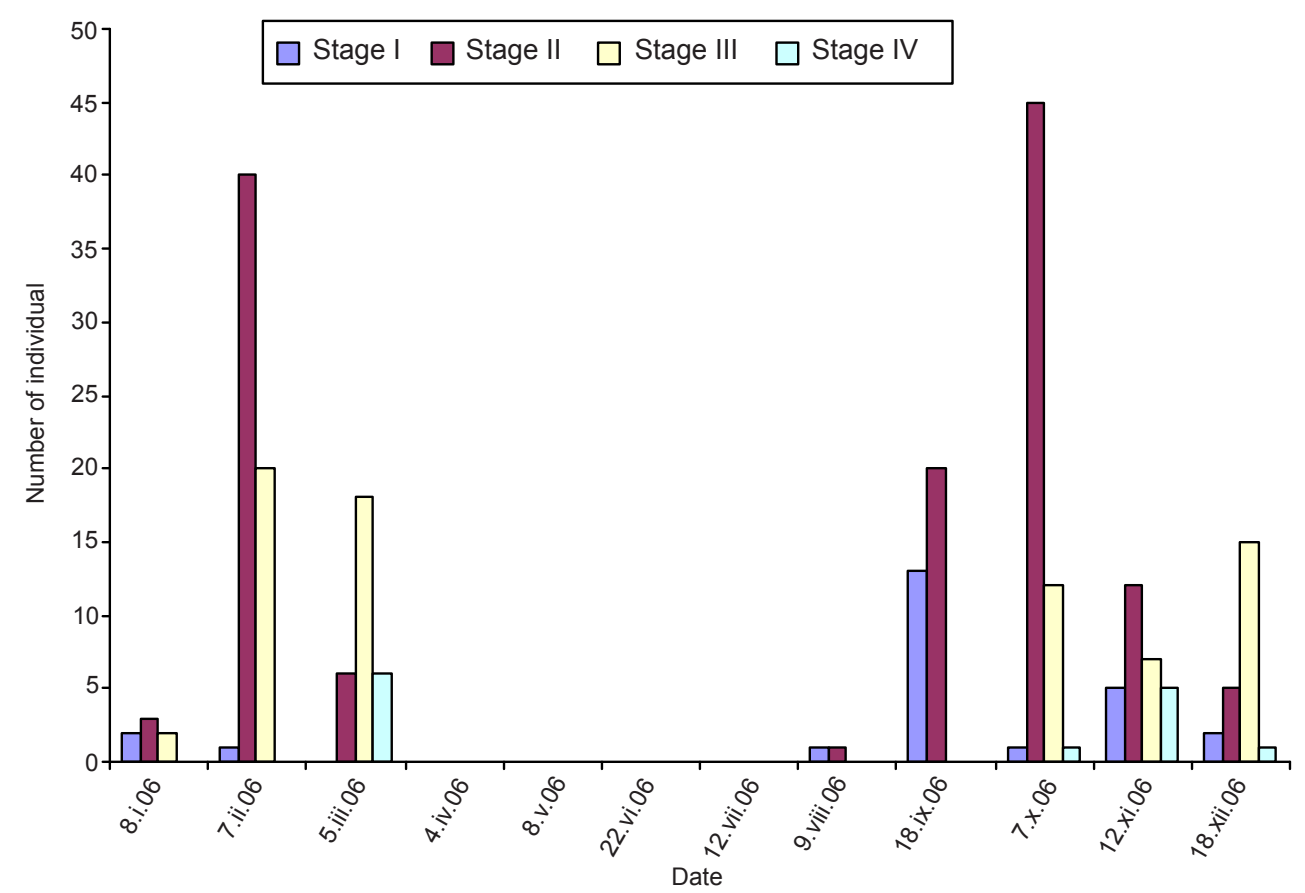

Figure 1. Life cycle of Epeorus sp.

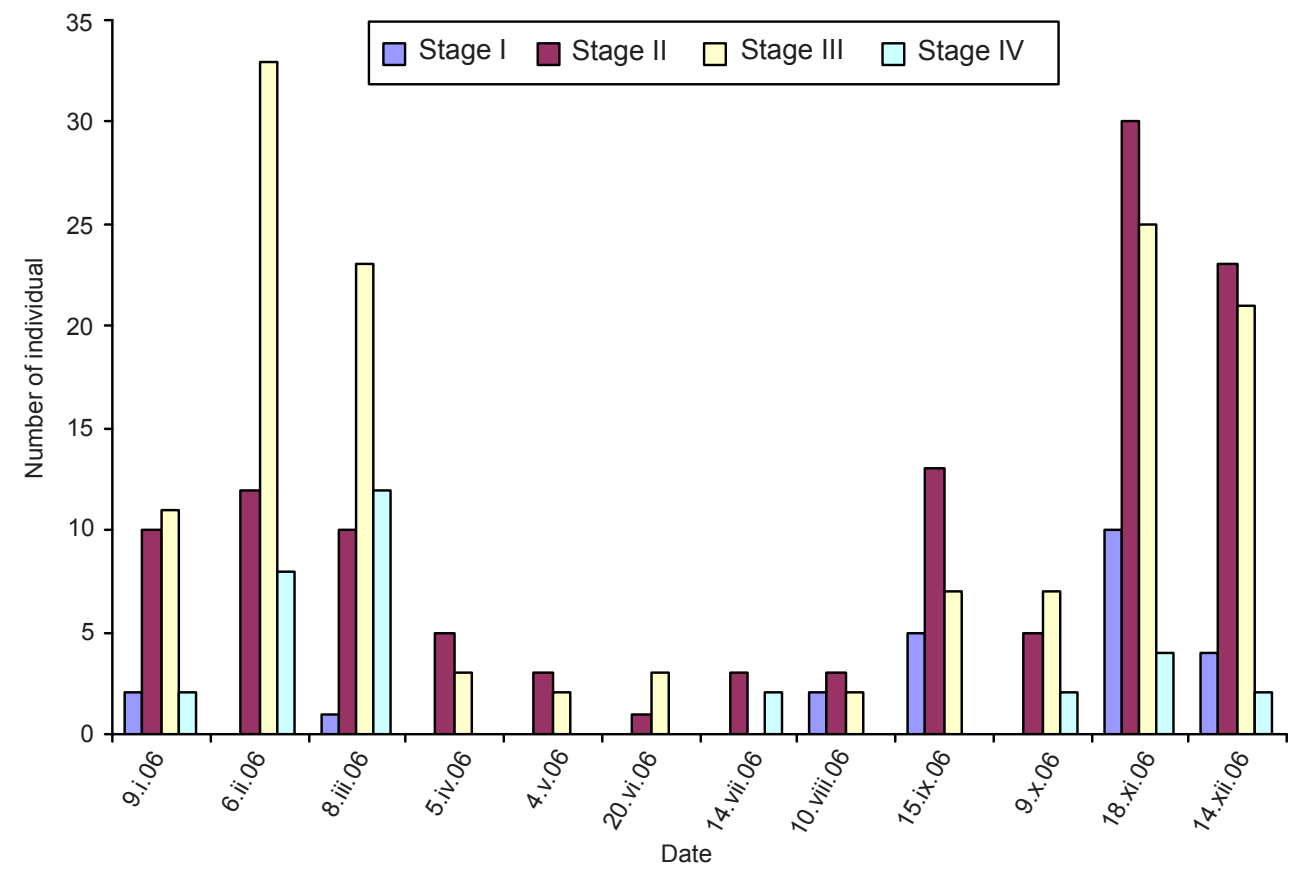

Figure 2. Life cycle of Afronurus kumbakkaraiensis

\section{Results and Discussion}

Hynes (1961) and Landa (1968) proposed a classification of life cycles of the European mayflies and that has been used by Clifford et al. (1973) to classify life cycles of some Canadian mayflies as follows:

$A_{1}$ (Winter species): Nymphs hatch in summer and autumn, continue to grow throughout the winter and emerge the following spring or summer.

$A_{2}$ (Summer species): Nymphs hatch, grow and emerge during a short period of summer, the eggs being in a supposedly diapause state for most of the year.

$\mathrm{A}_{3}$ (Winter species): Nymphs hatch and grow in summer and autumn only. Growth occurs in the following spring. 


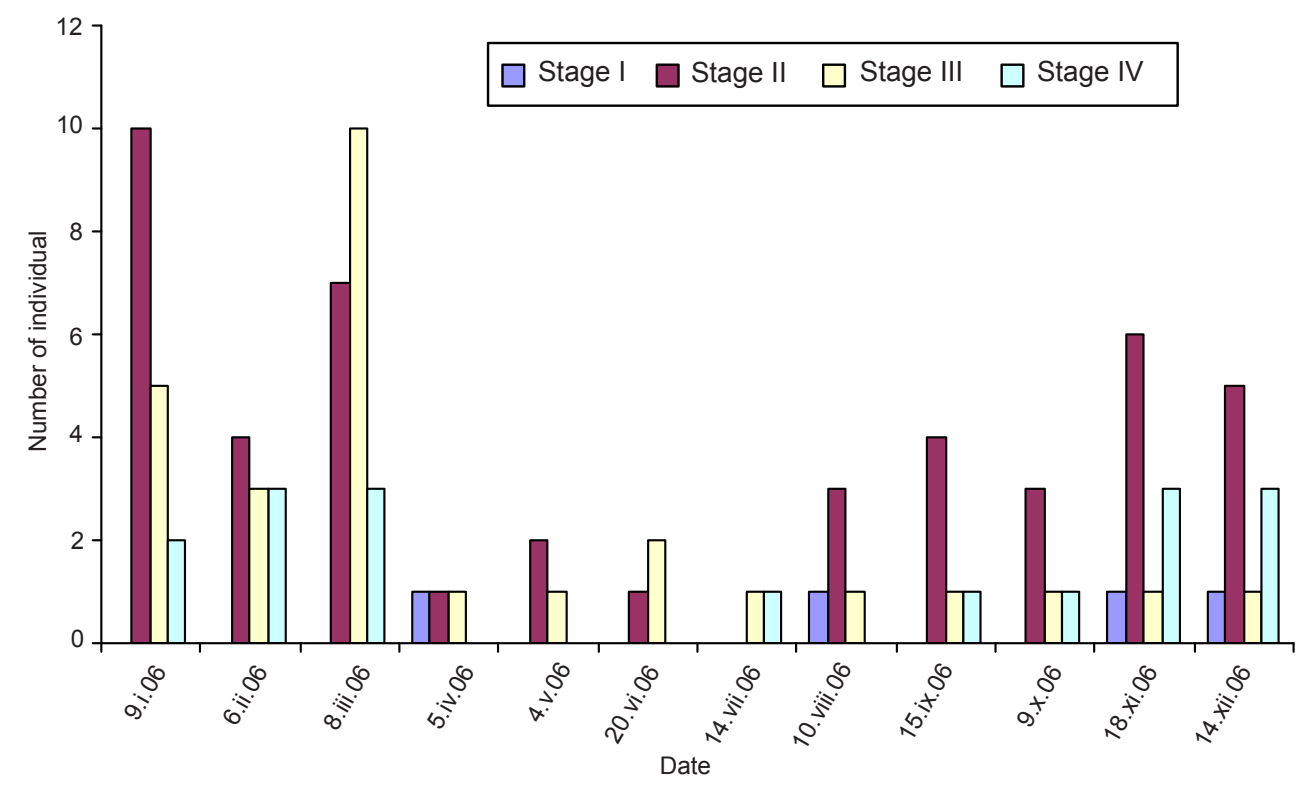

Figure 3. Life cycle ofThalerosphyrus flowersi

B. Two or more generations in a year.

C. One generation in two or more years.

D. Others.

Going from the equator to the arctic, the Life cycle patterns of mayfly fauna change from equator to arctic. Species with multivoltine cycles (tropics), to species having one-year cycles with growth during most of the year (moderate-temperate regions to species having oneyear cycles with most of the growth restricted to a short period of the year (cold-temperate and subarctic regions) and finally to one-year cycles with hatching, growth and emergence restricted to a very short part of the year (arctic) (Clifford et al. 1973).

Life cycle patterns of Epeorus sp., Afronurus kumbakkaraiensis and Thalerosphyrus flowersi in Kumbakkarai stream are interpreted from the developmental stage frequency histograms (Figs. 1-3). There is probably a preponderance of species with multivoltine cycles (B-species according to Landa's classification) in tropics (Clifford et al. 1973). The life cycle pattern of the two species Afronurus kumbakkaraiensis and Thalerosphyrus flowersiare basically multivoltine with asynchronous, overlapping generations and continuous emergence. It is of interest to compare the investigations of Sivaramakrishnan \& Job (1981) on the life cycle patterns of Petersula courtallensis and Notophlebia jobi in Courtallam with the present investigated species. In these species also, hatching was continuous and development asynchronous and independent of any cyclical pattern. Dwindling of Afronurus kumbakkaraiensis and Thalerosphyrus flowersi. Ide (1935) believed that eggs of certain mayfly species remain dormant during summer and those that hatch early are killed by high temperature. Also low oxygen level in the stream water in summer may be detrimental to the early instar nymphs (Pescador \& Peters 1974). The temperature of the Kumbakkarai Stream water temperature climbed up to $31^{\circ} \mathrm{C}$ during summer and oxygen level was $5 \mathrm{mg} / \mathrm{l}$. Clifford et al. (1973) found that temperature independently or along with photoperiod can influence mayfly life cycle patterns predictably. Temperate Heptageniids normally have univoltine life histories (Clifford 1982) although some species have been reported to complete two generations in a year (Benke \& Jacobi 1986; Jacobi \& Benke 1991).

The life cycle pattern of Epeorus sp. differs from the other two Heptageniids. Adults emerged from October to December. Hatching of nymphs apparently occurs during monsoon periods. Eggs laid by females emerging early in the flight period, hatch in the same year. These nymphs grow and emerge during early summer explaining the appearance of a few large and many tiny nymphs in summer. Field investigations reveal that Epeorus sp. takes two to three months to complete life cycle.

The life cycle of Epeorus sp. may have more than one univoltine brood since part of the eggs hatch in north-east monsoon period and the rest hatch the following summer. Similar type of life cycle is met within Heptagenia diabasia, Heptagenia hebe and Stenacron interpunctatum in Wisconsin which have more than one univoltine brood since part of the eggs hatch in fall and the rest hatch the following spring. Life history studies of Dobbrin \& Giberson (2003) on Epeorus pleuralis and Epeorus fragilis showed that both are univoltine species. Epeorus sp. is classified into $\mathrm{A}_{3}$ group as per Landa's classification. Complete absence of Epeorus sp. in late summer and early southwest monsoon period may be due to the following reasons: 
(a) During these periods the mean current velocity at the sampling site was only $0.1 \mathrm{~m} / \mathrm{sec}$. Epeorus sp. being a rheotactic form may not have tolerated a low current velocity, possibly migrated upstream where the current velocity was bearable. Minshall (1967) also found that very slow current velocities unfavourable to Epeorus pleuralis nymphs. The cooler upstream conditions with increased current velocity may be a preferred condition.

(b) Egg diapause has been studied in detail in Ephemerella ignita and Baetis vernus (Bohle 1969, 1972). Epeorus sp. being basically a temperate form may have the genetic capacity to enter diapauses, not necessarily, every year. There is a possibility of egg diapause, but the absence of small nymphs in field but as Brittain (1982) observes, need not be the indicator of it.

(c) Normal sampling method allowing free movement of small nymphs, might not have been suitable.

\section{REFERENCES}

Bengtsson, B.E. (1981). The growth of some Ephemeropteran nymphs during winter in a North Swedish river. Aquatic Insects 3: 199- 208.

Benke, A.C. \& D.I. Jacobi (1986). Growth rates of mayflies in a sub tropical river and their implication for secondary production. Journal of North American Benthological Society 5: 107-114.

Bohle, H.W. (1969). Untersuchungen uber die Embryonalent wicklung und die embryonale Diapause bei Baetis vernus Curtis und Baetis rhodani Pictet (Baetidae, Ephemeroptera). Zoologische Jahrbuecher Abteilung fuer Anatomie und Ontogenie der Tiere 86: 493-575.

Bohle, H.W. (1972). Die temperatuabhangigkeit der Embryogeness und der embryonalen Diapause von Ephemerella ignita (Pode) (Insecta, Ephemeroptera). Oecologia 10: 253-268.

Brittain, J.E. (1982). Biology of mayflies. Annual Review of Entomology 27: 119-147.

Clifford, H.F. (1969). Limnological features of a northern brown water stream, with special reference to the life histories of the aquatic insects. American Midland Naturalist 82: 578-597.

Clifford, H.F., M.R. Robertson \& K.A. Zelp (1973). Life cycle patterns of mayflies (Ephemeroptera) from some streams of Alberta, Canada. Proc. $1^{\text {st }}$ Int. conf. Ephemeroptera, 1970, 122-131pp.

Dobbrin, M. \& D.J. Giberson (2003). Life history and production of mayflies, stoneflies and caddisflies (Ephemeroptera, Plecoptera and Trichoptera) in a spring - fed stream in
Prince Edward island, Canada: evidence for population asynchrony in spring habitat. Canadian Journal of Zoology 81: 1083-1095.

Dudgeon, D. (1992). Patterns and process in stream ecology. A synoptic review of Hong Kong running waters. E. Schweizerbart'sche Verlagsbuchhandlung (Nägele u. Obermiller). Stuttgart: 1-147.

Dudgeon, D. (1996). Lifehistories, secondary production, and microdistribution of heptageniid mayflies (Ephemeroptera) in a tropical forest stream. Journal of Zoology 240: 341-361.

Flowers, R.W. \& W.L. Hilsenhoff (1978). Life cycles and habitats of Wisconsin Heptageniidae (Ephemeroptera). Hydrobiologia 60: 159-171.

Hynes, H.B.N. (1961). The invertebrates fauna of a Welsh mountain stream. Archiv für Hydrobiologie 57: 344-388.

Harker, J.E. (1952). A study of the life cycles and growth-rates of four species of Mayflies. Proceedings of Royal Entomological Society London 27: 77-114.

Ide, F.P. (1935). The effect of temperature on the distribution of the mayfly fauna of a stream. Publications of the Ontario Fisheries Research Laboratory 50: 1-76.

Jacobi, D.I. \& A.C. Benke (1991). The life histories and abundance patterns of snage dwelling mayflies in a black water Coastal Plain river. Journal of North American Benthological Society 10: 372-387.

Landa, V. (1968). Developmental cycles of central European Ephemeroptera and their interrelations. Acta Entomologica Bohemoslovaca 65: 276-284.

Mc Cafferty, W.P. \& B.L. Huff, Jr. (1978). The life cycle of the mayfly Stenacron interpunctatum ( Ephemeroptera: Heptageniidae). Great Lakes Entomologist 11: 209-216.

Minshall, J.N. (1967). Life history and ecology of Epeorus pleuralis (banks) (Ephemeroptera; Heptageniidae). American Midland Naturalist 78: 369-388

Olechowska, M. (1981). Life cycle of Rhitrogena loyolaea (Navás) (Ephemeroptera, Heptageniidae) in the Stream Strazyski in the Tatra Mts. Acta Hydrobiologica 23(1): 69-76.

Pescador, M.L. \& W.L. Peters (1974). The life history and ecology of Baetisca rogersi Berner (Ephemeroptera: Baetiscidae). Bulletin of Florida State Musium 17:151-209.

Rawlinson, R. (1939). Studies on the life history and breeding of Ecdyonurus venosus (Ephemeroptera). Proceedings of the Zoological Society 109: 377-450.

Salas, M. \& D. Dudgeon (2003). Life histories, production dynamicsand resource utilization of mayflies (Ephemeroptera) in two tropical Asian forest streams. Freshwater Biology 48: 485-499.

Sivaramakrishnan, K.G. \& S.V. Job (1981). Studies on mayfly populations of Courtallam streams. Proceedings of Symposium on Ecology and Animal Population, Zoological Survey of India 2: 105-116. 